This article was downloaded by: [National Taiwan University]

On: 3 September 2009

Access details: Access Details: [subscription number 908165602]

Publisher Taylor \& Francis

Informa Ltd Registered in England and Wales Registered Number: 1072954 Registered office: Mortimer House, 37-41 Mortimer Street, London W1T 3JH, UK

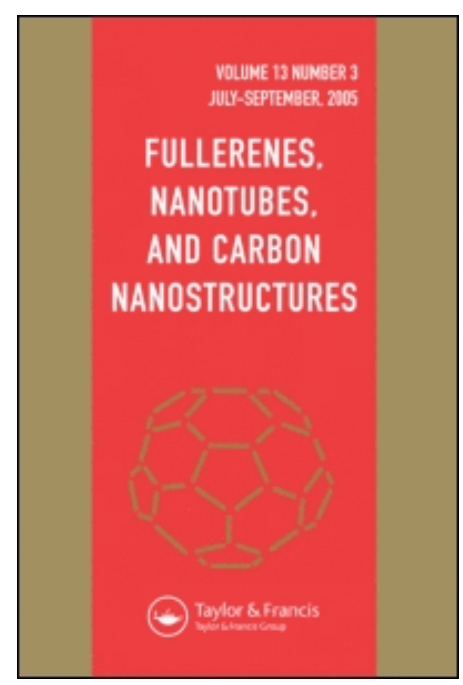

Fullerenes, Nanotubes and Carbon Nanostructures

Publication details, including instructions for authors and subscription information:

http://www.informaworld.com/smpp/title content=t713597253

\title{
Electron Spin Resonance and Infrared Spectroscopy Study of the Polyvinylpyrrolidone- $\mathrm{C}_{60}$ Composite
}

Chen Yu-Huei a; Ilias I. Khairullin a; Suen Mei-Po ab; Hwang Lian-Pin ab

a Department of Chemistry, National Taiwan University, and Institute of Atomic and Molecular Sciences, Academia Sinica, Taipei, Taiwan, Republic of China ${ }^{b}$ Electrical and Computer Engeeniring Department, New Jersey Institute of Technology, University Heights, Newark, NJ, U.S.A.

Online Publication Date: 01 September 1999

To cite this Article Yu-Huei, Chen, Khairullin, Ilias I., Mei-Po, Suen and Lian-Pin, Hwang(1999)'Electron Spin Resonance and Infrared Spectroscopy Study of the Polyvinylpyrrolidone- $\mathrm{C}_{60}$ Composite',Fullerenes, Nanotubes and Carbon Nanostructures,7:5,807 — 823 To link to this Article: DOI: $10.1080 / 10641229909351380$

URL: http://dx.doi.org/10.1080/10641229909351380

\section{PLEASE SCROLL DOWN FOR ARTICLE}

\footnotetext{
Full terms and conditions of use: http://www.informaworld.com/terms-and-conditions-of-access.pdf

This article may be used for research, teaching and private study purposes. Any substantial or systematic reproduction, re-distribution, re-selling, loan or sub-licensing, systematic supply or distribution in any form to anyone is expressly forbidden.

The publisher does not give any warranty express or implied or make any representation that the contents will be complete or accurate or up to date. The accuracy of any instructions, formulae and drug doses should be independently verified with primary sources. The publisher shall not be liable for any loss, actions, claims, proceedings, demand or costs or damages whatsoever or howsoever caused arising directly or indirectly in connection with or arising out of the use of this material.
} 


\title{
ELECTRON SPIN RESONANCE AND INFRARED SPECTROSCOPY
} STUDY OF THE POLYVINYLPYRROLIDONE-C ${ }_{60}$ COMPOSITE

\author{
Yu-Huei Chen, Ilias I. Khairullin, $\left.{ }^{\dagger}\right)$ Mei-Po Suen and Lian-Pin Hwang ${ }^{*}$ )
}

\author{
Department of Chemistry, National Taiwan University, \\ and Institute of Atomic and Molecular Sciences, Academia Sinica, \\ P.O. Box 23-34, Taipei, Taiwan, Republic of China
}

\begin{abstract}
Recently we have found from ESR spectra that the electron charge transfer take place in the polyvinylpyrrolidone- $\mathrm{C}_{60}$ composite. In this paper the polystyrene- $\mathrm{C}_{60}$, polyvinylchloride- $\mathrm{C}_{60}$, poly(ethylene glycol)- $\mathrm{C}_{60}$, and poly(ethylene oxide)- $\mathrm{C}_{60}$ composites are prepared and probed by the ESR technique for comparison. They show no signal which might be referred to the electron transfer. Along with this, we continue ESR study of the polyvinylpyrrolidone- $\mathrm{C}_{60}$ composite and also present IR spectra, which indicate the involvement of the carbonyl group of polyvinylpyrrolidone into the electron charge transfer process.
\end{abstract}

* To whom correspondence should be addressed.

$\uparrow$ This work was conducted during I.I.Kh.'s stay at IAMS, Academia Sinca, on leave from Department of Thermal Physics, Uzbekistan Academy of Sciences, 28 Katartal, Chilanzar, Tashkent, 700135, Uzbekistan.

Present address: Electrical and Computer Engeeniring Department, New Jersey Institute of Technology, University Heights, Newark, NJ 07102-1982, U.S.A. 


\section{Introduction}

The non-conjugated polymer- $\mathrm{C}_{60}$ systems have drawn little attention comparing to those containing conjugated polymers. The latter systems attract steady interest due to the great potential for electronic industry. ${ }^{1-4}$ In turn, the non-conjugated polymer- $\mathrm{C}_{60}$ systems may be important for future biological and medical applications. ${ }^{5}$ Recent progress toward biological applicability of $\mathrm{C}_{60}$ is related to promotion solubility of $\mathrm{C}_{60}$ in polar solvents. Actually, many authors achieve the result with the inclusion of $\mathrm{C}_{60}$ by non-polymer compounds such as $\gamma$ cyclodextrin, ${ }^{6}$ artificial lipid membranes, ${ }^{7}$ and 1,4-diazabicyclooctane. ${ }^{8}$ The nonconjugated polymer polyvinylpyrrolidone (PVP) was the first one employed recently for solubilization of $\mathrm{C}_{60}$ into water. ${ }^{5}$ Though the existence of the interaction between $\mathrm{C}_{60}$ and PVP is obvious, the pertinent mechanism must be clarified. In the conjugated polymer- $\mathrm{C}_{60}$ system, this interaction occurs often through the electron charge transfer from polymer to $\mathrm{C}_{60}{ }^{1-4,9,10}$ Usually, such electron transfer is initiated by photoexcitation..$^{1-4}$ On the other hand, it is doubtful whether such mechanism take place in the non-conjugated polymer- $\mathrm{C}_{60}$ systems. Besides, $\mathrm{C}_{60}$ is a strong electron acceptor, ${ }^{11}$ and hence one may expect the charge transfer interaction if a non-conjugated polymer possesses an appropriate functional group with the electron donation ability. Actually, we have found recently characteristic ESR signals in the PVP-C $\mathrm{C}_{60}$ system and interpreted them in terms of the electron charge transfer mechanism. ${ }^{12}$

In this paper, a number of the reference composites of $\mathrm{C}_{60}$ with various nonconjugated polymers are prepared for comparison. They show the lack of the ESR signal which could be referred to the electron charge transfer. In order to obtain further details regarding PVP-C $\mathrm{C}_{60}$, we continue ESR experiments and also examine its IR spectra. 


\section{Experimental}

$\mathrm{C}_{60}$ (of $99.9 \%$ purity) and PVP were purchased from Material and Electrochemical Research Corp. (Arizona, USA) and from Acros (New Jersey, USA), respectively. Two types of PVP, with average $M_{w} c a .40,000$ (K30) and 360,000 (K90), were employed. Different type of PVP shown in the parentheses will be used in the text to represent the differences in molecular weight. In a typical preparation, solution of $\mathrm{C}_{60}$ in toluene $(10 \mathrm{mg}, 20 \mathrm{ml})$ was added to solution of PVP in $\mathrm{CHCl}_{3}(1 \mathrm{~g}, 40 \mathrm{ml})$. Mixture was stirred intensively to obtain transparent solution. Thereafter, solvent was evaporated at $60{ }^{\circ} \mathrm{C}$ under dynamic vacuum of about 100-200 torr. The residue was finally lyophilized to produce transparent light-brown solid composite. In a number of preparations, commercial $\mathrm{C}_{60}$ was preheated at $300^{\circ} \mathrm{C}$ for $5-10$ hours under dynamic vacuum of about $10^{-5}$ torr to reduce residual paramagnetic signal. For the sake of comparison, the samples of pristine PVP for IR measurements were prepared with the same toluene/ $\mathrm{CHCl}_{3}$ ratio, and the solvent was withdrawn at the low evaporating rate as well. Polyvinylchloride of the inherent viscosity 1.02 was purchased from Scientific Polymer Inc. (Japan) and dissolved in THF, poly(ethylene glycol) (average $\mathrm{M}_{\mathcal{W}}$ ca. 8,000) and poly(ethylene oxide) (average $\mathrm{M}_{\mathcal{W}} c a .600,000$ ) were purchased from Aldrich and dissolved in benzene. Polystyrene was purchased from Nippon Shiyaqo Kotyo (Japan) and dissolved in toluene. The composites of $\mathrm{C}_{60}$ with polyvinylchloride, poly(ethylene glycol) poly(ethylene oxide) and polystyrene were prepared similarly to the PVP- $\mathrm{C}_{60}$ composite.

ESR spectra were measured on the X-band ESR spectrometer Bruker ESP$300 \mathrm{E}$. The spectral area at a given temperature, $J(T)$, was derived by the double integration of the ESR spectra employing software of a computer Bruker ESP1600. The concentration of spins was determined at room temperature (RT) with reference to the 2,2-diphenyl-1-picrylhydazyl (DPPH) sample of known spin 
content. The $g$ value was measured with reference to $g=2.0036$ of DPPH. The Bruker double resonator provided the same experimental conditions for the sample under study and the DPPH reference. Magnetic field was monitored by a NMR Gaussmeter Bruker ER035 with an accuracy of \pm 0.05 G. The temperature controller setup enabled the variation of temperature within 100-360 K. Spectra at $77 \mathrm{~K}$ were taken in liquid $\mathrm{N}_{2}$. Infrared spectra were taken in air on a Bomem MB155 FT-IR/FT-Raman spectrometer. Experimental wavenumbers of the IR peaks as measured were then rounded off to an integer.

\section{Results and Discussion}

\subsection{Electron Spin Resonance Spectroscopy.}

3.1.1. The $g_{1}=2.0025 \pm 0.0001$ signal and role of oxygen. Composites of PVP- $\mathrm{C}_{60}$ as prepared exhibited primarily the ESR signal with a $g$ value of $2.0025( \pm 0.0001)$ and a peak-to-peak linewidth $\Delta H_{\mathrm{pp}}=2.0-2.6 \mathrm{G}$. We will refer this signal as to $g_{1}$. Figure la shows a typical spectrum recorded from the sample of $\mathrm{PVP}-\mathrm{C}_{60}(\mathrm{~K} 30)$ placed in argon. The sample weight was $100 \mathrm{mg}$ containing 1 $\mathrm{mg}$ of $\mathrm{C}_{60}$. It has been prepared under the inert atmosphere with the degassed solvents and placed into the pyrex tube without exposure to air. We observed the same signal for the samples prepared with the regular solvents as well. At the same time, the sample of PVP alone showed the lack of any ESR signal. Thus, we assert that the appearance of $g_{1}$ is due to the incorporation of $\mathrm{C}_{60}$ with PVP. It has been reported in literature that pristine $\mathrm{C}_{60}$ demonstrates weak ESR signal ${ }^{13-19}$ which is referred to the influence of molecular oxygen. ${ }^{17.19}$ Figure $1 \mathrm{~h}$ shows the spectrum recorded from $1 \mathrm{mg}$ of pristine $\mathrm{C}_{60}$, where a weak signal with $g=2.0024( \pm 0.0001)$ and $\Delta H_{\mathrm{pp}}=1.0 \mathrm{G}$ corresponded to the concentration of spins $(4.2 \pm 0.5) \times 10^{16} \mathrm{spin} / \mathrm{g}$. The question arises whether $g_{1}$ in the composite represented the same spin species observed in pristine $\mathrm{C}_{60}$. For comparison, the 
integrated intensity of $g_{1}$ (Fig. 1a) led to the concentration of spins of $(8.0 \pm 0.5) \times 10^{17} \mathrm{spin} / \mathrm{g}$ of $\mathrm{C}_{60}$ which is at least an order of magnitude larger than that in pristine $\mathrm{C}_{60}$. In order to ascertain whether the stronger and broader $g_{1}$ associated with the inherent feature of PVP- $\mathrm{C}_{60}$, composites of $\mathrm{C}_{60}$ with polyvinylchloride, poly(ethylene glycol), poly(ethylene oxide), and polystyrene were prepared analogously. It should be noted that for these samples no special care had been taken to avoid the influence of the air oxygen. Similarly to PVP$\mathrm{C}_{60}, 100 \mathrm{mg}$ of each reference composite containing $1 \mathrm{mg}$ of $\mathrm{C}_{60}$ was placed into the pyrex tube. The reference composites showed signals with the same $g=2.0024 \pm 0.0001$ indeed, but with concentration of spins as weak as that of pristine $\mathrm{C}_{60}$. The signal linewidth for these composites was $1.0-1.5 \mathrm{G}$, also similar to that of pristine $\mathrm{C}_{60}$ and apparently narrower than the signal of PVP-C $60^{\circ}$ Corresponding ESR spectra with the same scale as for PVP- $\mathrm{C}_{60}$ sample are presented in Figs. 1i to $1 \mathrm{k}$ for comparison. Thus, even prepared in air, the reference composites had the spin concentration much smaller than that of PVP$\mathrm{C}_{60}$. To explain these results, we suggest that along with the residual molecular oxygen, the carbonyl oxygen of PVP forms the pair with the nearest $\mathrm{C}_{60}$ molecule. Additional spin species may localize on those carbonyl oxygen- $\mathrm{C}_{60}$ pairs and may contribute into $g_{1}$.

3.1.2. ESR spectra at room temperature. The ESR spectra did not change apparently when the samples of PVP-C $\mathrm{C}_{60}$ composites were kept in air or under the inert atmosphere for several months. However, spectra changed dramatically at the moment when samples were evacuated and heated. A second signal with a $g$ value of $2.0004( \pm 0.0001)$ and $\Delta H_{p p}=1.6 \mathrm{G}$ arose in the RT spectra (Fig. 1b) when the tubes were evacuated for a few hours at $10^{-5}$ torr and then sealed off. We will refer this signal to $g_{2}$. The $g_{2}$ continued to grow at room temperature during 


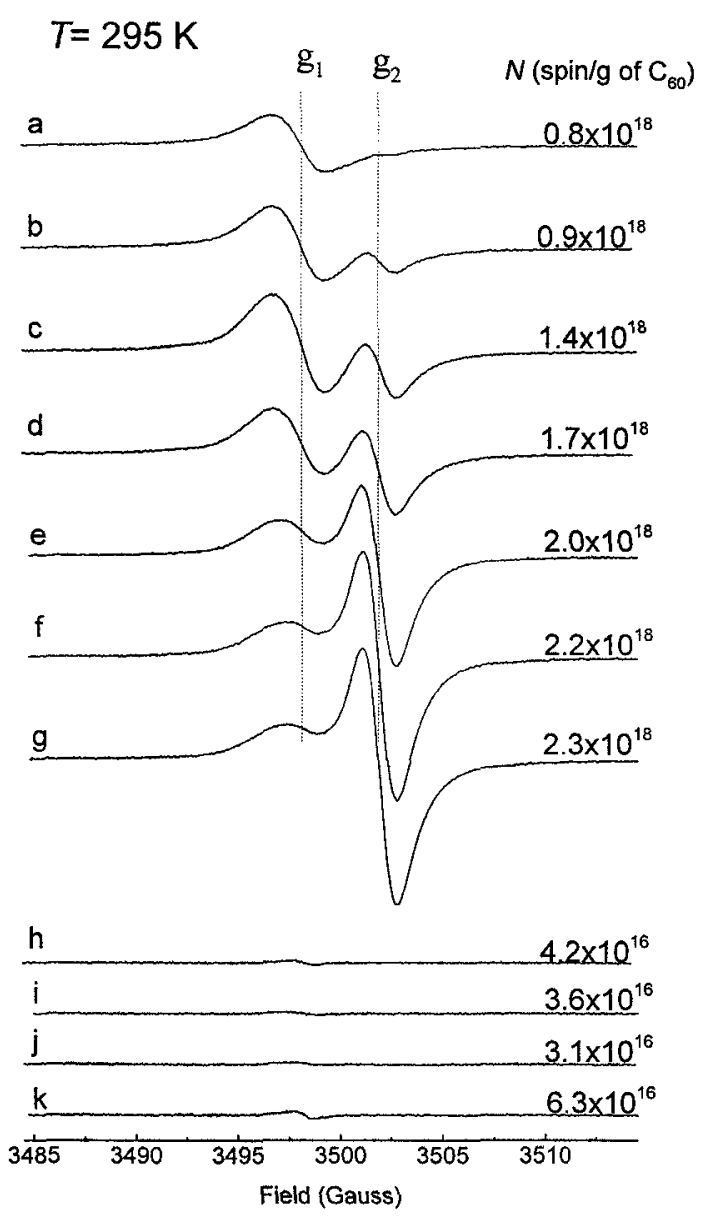

FIG 1 - Room temperature ESR spectra for PVP- $\mathrm{C}_{60}(\mathrm{~K} 30)(\mathrm{a}-\mathrm{g})$, pristine $\mathrm{C}_{60}(\mathrm{~h})$, $\mathrm{C}_{60} /$ polystyrene (i), $\mathrm{C}_{60} /$ polyvinylchloride $(\mathrm{j})$, and $\mathrm{C}_{60} /$ poly(ethylene oxide) (k). For PVP-C $\mathrm{C}_{60}(\mathrm{~K} 30)$ : (a) a newly prepared composite in argon; (b) after evacuation at RT for 6 hours at $5 \times 10^{-5}$ torr; (c) after 24 hours at RT in the sealed tube; (d) after 6 days at RT in the sealed tube; (e) heated afterwards at $60^{\circ} \mathrm{C}$ for 2 hours; (f) further heated at $60^{\circ} \mathrm{C}$ for 24 hours; (g) heated at $60^{\circ} \mathrm{C}$ for 3 days. The estimated concentration of spins per gram of $\mathrm{C}_{60}$ are indicated to the right. For all composites, the sample weight was $100 \mathrm{mg}$ consisting of $1 \mathrm{mg}$ of $\mathrm{C}_{60}$. For comparison, the spectrum (h) was recorded from $1 \mathrm{mg}$ of $\mathrm{C}_{60}$. The reference composites and pristine $\mathrm{C}_{60}$ were in air. Spectra were recorded with the accumulation as many as 20 times and with the same gain, $P_{\mathrm{mw}}=1 \mathrm{~mW}$ and $\Delta H_{\text {mod }}=0.5 \mathrm{G}$. 
several days after the tubes had been sealed (Figs. 1c and 1d). The signal further increased with several annealings performed for a few days at $60{ }^{\circ} \mathrm{C}$ (Figs. 1e to 1g). We have proved already ${ }^{12}$ that $g_{2}$ was not caused by radicals which might form during pyrolysis of the polymer but related to the presence of $\mathrm{C}_{60}$. The nature of this new signal has been associated with the interaction between PVP and $\mathrm{C}_{60}$. The most important result of present study is that the reference composites, analogously evacuated and annealed, do not exhibit the $g_{2}$ signal in their ESR spectra. Thus, one may suggest that the reason for the $g_{2}$ appearance may relate to the distinction in the functional group of PVP compared to those of the reference polymers.

\subsubsection{Transformations of the room temperature ESR spectra with the} $\mathrm{O}_{2} / \mathrm{H}_{2} \mathrm{O}$ treatment. Figure 2 presents spectra of PVP-C $\mathrm{C}_{60}(\mathrm{~K} 90)$ recorded at different stages of the $\mathrm{O}_{2} / \mathrm{H}_{2} \mathrm{O}$ treatment. The initial spectrum taken in vacuum is shown in Fig. $2 \mathrm{a}$ by a solid line. Then, the composite was exposed to $\mathrm{O}_{2}$. This brought about dramatic growth of $g_{1}$ (the dashed line in Fig. 2a). The superposition of the high-field wing of $g_{1}$ accounted for the minor decrease in $g_{2}$. Thereafter, the sample was re-evacuated at RT for 2 hours under $5 \times 10^{-4}$ torr. Spectrum taken at this point is shown in Fig. $2 \mathrm{~b}$ by a solid line which almost matched the initial spectrum (the solid line in Fig. 2a). It is believed that evacuation for a longer time removes most of $\mathrm{O}_{2}$ introduced into the sample and restores the initial spectrum almost completely. Afterwards, this sample was exposed to the vapor of the degassed water for a few minutes, and the corresponding ESR spectrum taken from the wet sample is displayed in Fig. 2b by a dashed line. Result was entirely different from the sample with exposure to $\mathrm{O}_{2}$. The $g_{1}$ remained constant while $g_{2}$ apparently decreased. However, the latter one did not vanish completely in the wet sample as we expected (Fig. 2b). One may explain this by the inhomogeneous distribution of the absorbed water. The 


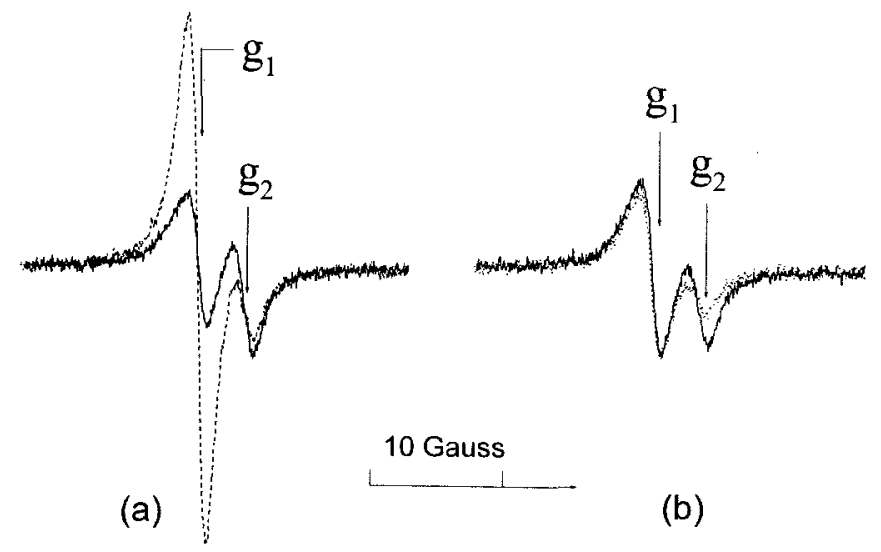

FIG 2 - Variation of the ESR spectra of PVP-C $\mathrm{C}_{60}(\mathrm{~K} 90)$ with the $\mathrm{O}_{2} / \mathrm{H}_{2} \mathrm{O}$ treatment: (a) a solid line is for the sample in vacuum, a dashed line is for the sample exposured to $\mathrm{O}_{2}$ (b) a solid line is for the sample vacuumed for 2 hours at RT under $5 \times 10^{-4}$ torr after the exposure to $\mathrm{O}_{2}$, a dashed line is for the sample exposured for a few minutes to vapor of the oxygen-free water.

remainder of $g_{2}$ was presumably from the dry areas left in the bulk. Thus, water absorbed by the composite affected $g_{2}$, while oxygen affected $g_{1}$ mainly.

Summarizing experiment with the $\mathrm{O}_{2} / \mathrm{H}_{2} \mathrm{O}$ treatments, one may conclude that the polymer conformation should play a vital role in providing appropriate conditions for interaction of $\mathrm{C}_{60}$ with PVP. Consequently, the withdrawal of the residual solvent and heating of the composite at $60^{\circ} \mathrm{C}$ ascribed above may lead to the modification of the polymer conformation and, as a result, to the appearance of $g_{2}$ (Fig. 1).

3.1.4. ESR spectra at low temperatures. Figure 3 presents the temperature variation of the ESR spectra of PVP-C $60(\mathrm{~K} 30)$. Below about $120 \mathrm{~K}$, the $g_{2}$ splits into two components. A narrower component does not shift, while the second, broader one shifts toward high fields. To $77 \mathrm{~K}$, the latter components evolves into 


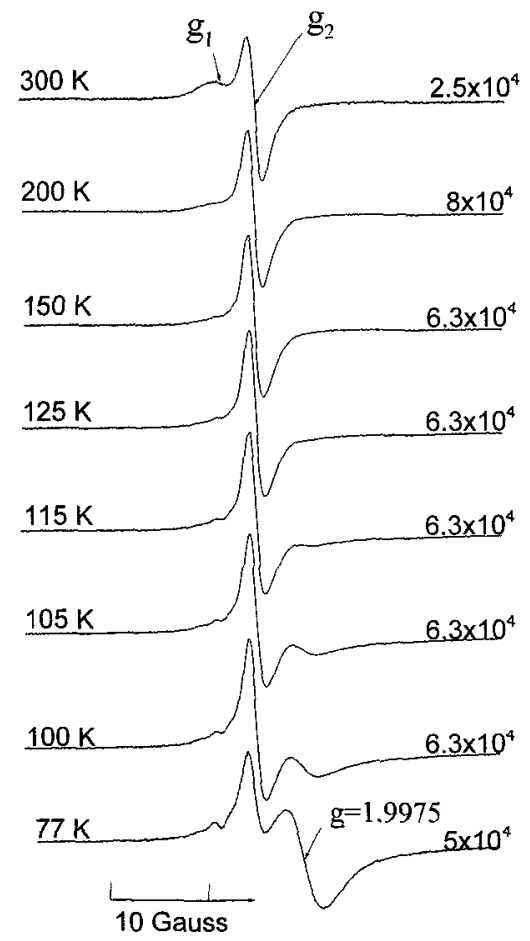

FIG 3 - Temperature variation of the ESR spectra for PVP- $\mathrm{C}_{60}(\mathrm{~K} 30)$. The RT spectrum for this sample is shown in Fig. $1 \mathrm{~g}$. Corresponding temperatures and receiver gains are indicated to the left and right respectively. $P_{m w}=1 \mathrm{~mW}$ and $\Delta H_{\text {mod }}=0.5 \mathrm{G}$.

the broad, asymmetric line with a $g$ value of 1.9975. Similar spectra were observed earlier using another sample of PVP-C $\mathrm{C}_{60} \cdot{ }^{12}$ With decrease of temperature, the sharp line with a $g$ value of 2.0025 emerges in the low-field wing of the spectra complementary to the broad component. Although its $g$ value coincides with that of $g_{1}$ seen at RT, it does not get saturated as easily as $g_{1}$.

In Fig. 4 we plot the spectral area normalized to that at $300 \mathrm{~K}, J(T) / J(300 \mathrm{~K})$, as function of temperature. Due to the strong superposition, it was difficult to 


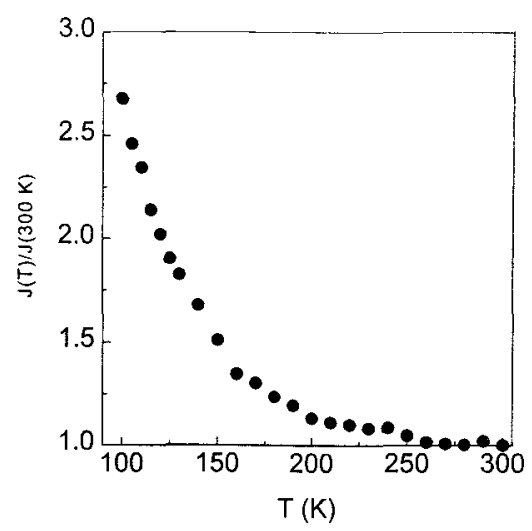

FIG 4 - Temperature variation of the spectral area normalized to that at $300 \mathrm{~K}$, $J(T) / J(300 \mathrm{~K})$. Data relate to the spectra presented in Fig. 3.

evaluate the inherent temperature behaviors of the major spectral components. Besides, an intensity of the narrower component calculated as the product of the signal peak-to-peak height, $I_{\mathrm{pp}}$, by $\left(\Delta H_{\mathrm{pp}}\right)^{2}$ obeyed a Curie law within the 130-300 $\mathrm{K}$ range (Fig. 5a). The drop in intensity below $130 \mathrm{~K}$ is a result of the superposition of the growing broad component. The linewidth and $g$ value of the narrower component remained almost constant within the $77-300 \mathrm{~K}$ range (Figs. 5b and 5c).

3.1.5. Assignment of ESR signals and the electron charge transfer. We have shown in Ref. 12 that $g_{1}$ and the two components evolved from $g_{2}$ demonstrated different microwave behaviors over the $77-300 \mathrm{~K}$ range. At $77 \mathrm{~K}$, the narrow component at position of $g_{2}$ got saturated with microwave power level above about $20 \mathrm{~mW}$. In opposite, the broad asymmetric line did not saturate with a microwave power level increased up to $200 \mathrm{~mW}$. The difference reflected distinct relaxation processes and proved that the signals at $77 \mathrm{~K}$ were originated 

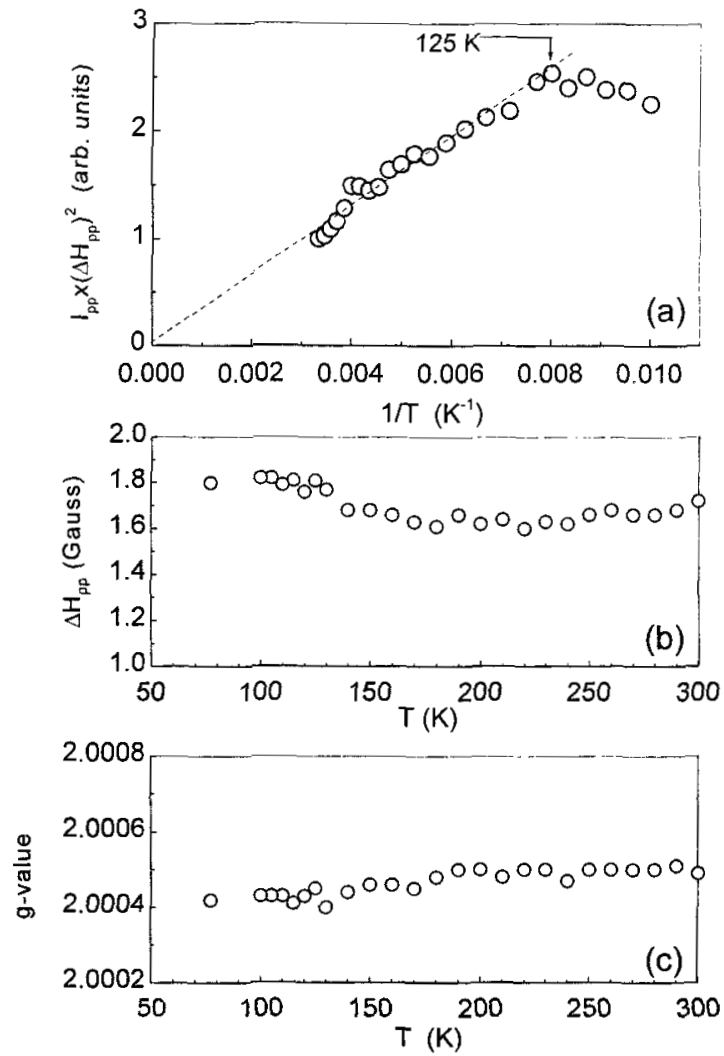

FIG 5 - The temperature variation of the ESR parameters for the $g_{2}$ signal in PVP$\mathrm{C}_{60}(\mathrm{~K} 30)$ : (a) the intensity as the product of the signal peak-to-peak height, $I_{\mathrm{pp}}$, by $\left(\Delta H_{\mathrm{pp}}\right)^{2}$, where a dashed line shows a Curie behavior; (b) a peak-to-peak linewidth $\Delta H_{\mathrm{pp}}$; (c) a $g$ value. Data relate to the spectra presented in Fig. 3.

by different spin species rather than by anisotropic magnetic parameters of the spectrum. We have mentioned also ${ }^{12}$ that one could detect $g_{2}$ (at RT) and both components (below $120 \mathrm{~K}$ ) reproducibly in all the evacuated and annealed samples regardless of the preparation history.

It has been proven in most publications that a low $g$ value, compared to those of all organic radicals, is a reliable probe for reduced $\mathrm{C}_{60}{ }^{24-30}$ For the $\mathrm{C}_{60}{ }^{-1}$ anion 
radical, $g$ value has been published to be about $1.997-2.000 .{ }^{24-30}$ Such low $g$ value has been related to the quenching of the angular momentum due to the Jahn-Teller distortion of the ground states of $\mathrm{C}_{60}{ }^{24}$ Owing to those results we conclude that the main contribution to $g_{2}$ is made by the $\mathrm{C}_{60}{ }^{-1}$ anion radical. Singh et al ${ }^{31}$ have reported a $g$ value of 1.9975 for the $\mathrm{C}_{60}{ }^{-1}$ anion radical in the oxygen- $\mathrm{C}_{60}$ pair. The same $g$ value obtained for the broad signal at $77 \mathrm{~K}$ also supports existance of $\mathrm{C}_{60}{ }^{-1}$ in the PVP-C 60 composite. The broadening of the signal to low temperatures may be explained by freezing of the reorientational motion of the radical and transition from the dynamic Jahn-Teller distortion to the static Jahn-Teller distortion. In other experiment, performed earlier, the ESR spectrum at $10 \mathrm{~K}$ showed strong anysotropic signal characterized $\mathrm{C}_{60}{ }^{-1}$ underwent the static Jan-Teller distortion. ${ }^{12}$ The nature of the narrow component at position of $g_{2}$ is not so obvious. It might associate with the $\mathrm{C}_{60}{ }^{-1}$ anion radicals, which still exhibit the dynamic Jahn-Teller effect at $77 \mathrm{~K}$, or relate to the counter radical localized on PVP.

\subsection{Infrared Spectroscopy.}

The IR spectra of the composites prepared from two types of polymer, PVP(K30) and PVP(K90), were similar in details. The spectra showed that a number of the polymer peaks shifted with respect to the corresponding peaks in the pristine polymer. Figure 6 exhibits two portions of typical spectra for $\mathrm{PVP}(\mathrm{K} 90)$ and the PVP-C ${ }_{60}(\mathrm{~K} 90)$ composite. The peak, which represented the $\mathrm{C}=\mathrm{O}$ stretching mode, ${ }^{21}$ shifted from $1669 \mathrm{~cm}^{-1}$ in the pristine polymer to 1662 $\mathrm{cm}^{-1}$ in the composite (Fig. 6a). A similar red-shift, from $1658 \mathrm{~cm}^{-1}$ for $\operatorname{PVP}(\mathrm{K} 30)$ to $1653 \mathrm{~cm}^{-1}$ for PVP- $\mathrm{C}_{60}(\mathrm{~K} 30)$, was observed in another experiment (spectra are not presented). Intensity of the peak at $1423 \mathrm{~cm}^{-1}$, assigned to the stretching mode of the $\mathrm{C}=\mathrm{N}$ partial double bond of $\mathrm{PVP},{ }^{21,22}$ decreased noticeably in the composite (Fig. 6b). On the other hand, the peak at $1462 \mathrm{~cm}^{-1}$ related to the 


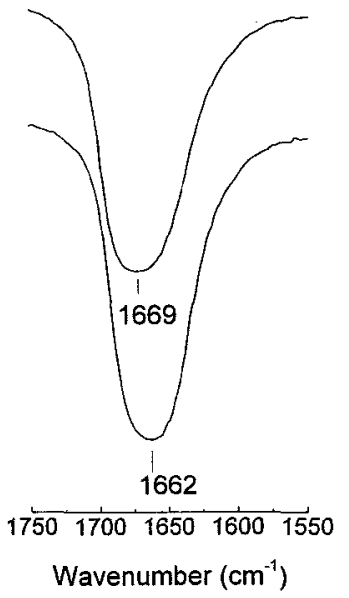

(a)

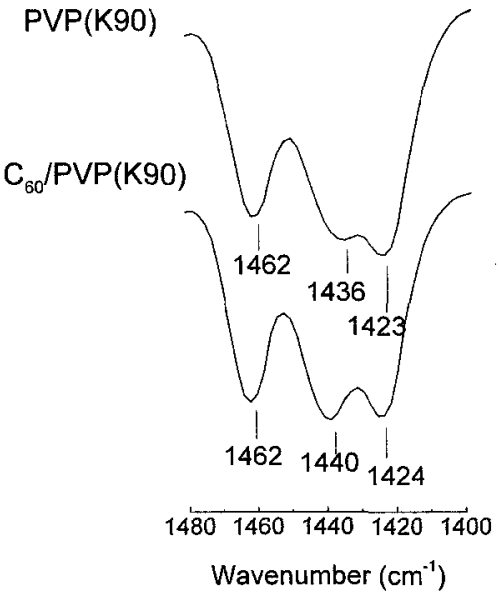

(b)

FIG 6 - Two portions of the infrared (IR) spectra of PVP and PVP-C 60 (K90) taken at RT: (a) there is a red-shift for the $\mathrm{C}=\mathrm{O}$ stretching mode of the carbonyl group, from $1669 \mathrm{~cm}^{-1}$ in the polymer to $1662 \mathrm{~cm}^{-1}$ in the composite; (b) no shift is observed for the $1462 \mathrm{~cm}^{-1}$ peak, which relates to the deformation mode of the $\mathrm{CH}_{2}$ group of the polymer backbone.

deformation mode of $\mathrm{CH}_{2}$ groups of the polymer backbone, ${ }^{23}$ showed no shift in the composite (Fig. 6b). However, it is quite uncertain in our case whether such a small quantity of $\mathrm{C}_{60}$ or the residual solvent in the sample could be the main cause to affect the stretching modes of the host PVP. Namely because of the latter suspicion, we compared the spectrum for PVP-C 60 with that of the same system in the absence of $\mathrm{C}_{60}$. Since PVP-C $\mathrm{C}_{60}$ and PVP were dissolved and dried under the same conditions, we conclude that the presence of $\mathrm{C}_{60}$ was the only cause for the difference in IR absorption between PVP- $\mathrm{C}_{60}$ and PVP. One may still argue that it is impossible to detect any change originated from $\mathrm{C}_{60}$ if the $\mathrm{C}_{60}$ molecule and carbonyl group is of one to one association. However, the polymer nature of PVP and a relatively big size of the fullerene molecule, compared to the chain unit, 
make it possible for one $\mathrm{C}_{50}$ to interact with several carbonyl groups belonged either to one or to different polymeric chains.

One may suggest that if the oxygen of the carbonyl group involves into the donation of electron, then some red-shift in the fundamental $\mathrm{C}=\mathrm{O}$ stretching mode may occur. For our PVP-C 60 samples, the red-shift is observed indeed, while the polymer backbone is not affected by the presence of $\mathrm{C}_{60}$. It is important to find that there was some correlation in a position of the $\mathrm{C}=\mathrm{O}$ peak and the water-vapor treatment. The red-shifted $\mathrm{C}-\mathrm{O}$ peak moved back to the shorter wavelength with the water-vapor treatment. For example, for PVP- $\mathrm{C}_{60}(\mathrm{~K} 30)$ the red-shifted peak moved from $1653 \mathrm{~cm}^{-1}$ back to $1668 \mathrm{~cm}^{-1}$ in the wet sample (not presented). At the same time, as it is shown above, the $g_{2}$ signal decreased in the RT ESR spectrum. It means that conditions at which the charge transfer process establishes are destroyed with the water-vapor treatment.

\section{Conclusion}

The ESR signal with a $g$ value of $2.0004( \pm 0.0001)$, assigned to the $\mathrm{C}_{60}{ }^{-1}$ anion radical, appears only in the PVP- $\mathrm{C}_{60}$ system. No such signal is found in the composites of $\mathrm{C}_{60}$ with polyvinylchloride, poly(ethylene glycol), poly(ethylene oxide), and polystyrene. These results along with the red-shift of the $\mathrm{C}=\mathrm{O}$ stretching mode in the IR spectra of PVP-C $\mathrm{C}_{60}$ enables one to suggest that donation of elecron occurs from the carbonyl group of PVP.

\section{Acknowledgments}

This work was supported by National Science Council of Republic of China under Grant No. NSC 85-2113-M-001-039. I.I.Kh. is grateful to National Science Council for fellowship. 


\section{References}

1. Sariciftci, N.S., Smilowitz, L., Heeger, A.J. and Wudl, F., Science, 1992, $\underline{258}, 1474$.

2. Sariciftci, N.S. and Heeger, A.J., Int. J. Mod. Phys. 1994, B 8, 237.

3. Morita S., Zakhidov, A.A. and Yoshino, K., Solid State Commun., 1992, 82, 249.

4. Yoshino, K., Yin, X.H., Akashi, T., Yoshimoto, K., Morita, S. and Zakhidov, A.A. Mol. Cryst. Liq. Cryst., 1994, 255, 197.

5. Yamakoshi, Y.N., Yagami, T., Fukuhara, K., Sueyoshi, S. and Miyata, N. J. Chem Soc., Chem. Commun., 1994, 4, 517.

6. Andersson, T., Nilsson, K., Sundahl, M., Westman, G. and Wennerstrom, O.J., Chem. Soc., Chem. Commun, 1992, 604.

7. Hungerbühler, H., Guldi, D.M, and Asmus, K.D., J. Am. Chem. Soc., 1993, $\underline{115}, 3386$.

8. Priyadarsini, K.I., Mohan, H., Tyagi, A.K. and Mittal, J.P., Chem.Phys. Letters, 1994, 230, 317.

9. Li, M. and Wan, M., Solid State Commun., 1995, 93, 681.

10. Lee, S.B., Zakhidov, A.A., Khairullin, I.I., Sokolov, V.Y., Khabibullaev, P.K., Akashi, T., Yoshino, M. and Yoshino, K., Proceed. EMRS Spring Meeting, Strashberg, May 1995.

11. Yoshida, Z., Dogane, I., Ikehira, H. and Endo, T., Chem. Phys. Lett. 1992, $\underline{201}, 4816$.

12. Khairullin, I.I., Chen, Y.-H. and Hwang, L.-P., Chem. Phys. Lett. 1997, 257, 1.

13. Tycko, R.R., Haddon, R.C., Dabbagh, G., Glarum, S.H., Douglass, D.C. and Mujsce, A.M., J. Phys. Chem., 1991, 95, 518. 
14. Yannoni, C.S., Johnson, R.D., Meijer, G.D., Bethune, S. and Salem, J.R., J. Phys. Chem., 1991, 95, 9.

15. Howard, A., Tomietto, M. and Wilkinson, D.A., J. Am. Chem. Soc., 1991, $\underline{113}, 7870$.

16. Byszewski, P., Stankowski, J., Trybula, Z., Kempinski, W. and Zuk, T., J. Molec. Struct., 1992, 269, 175.

17. Kawata, S., Yamauchi, K., Suzuki, S., Kikuchi, K., Shiromaru, H., Katada, M., Saito, K., Ikemoto, I. and Achiba, Y., Chem. Lett., 1992, 1659.

18. Pace, M.D., Christidis, T.C., Yin, J.J. and Milliken, J., J. Phys. Chem., 1992, $\underline{96}, 6855$.

19. Bartl, A., Dunsch, L., Kirbach, U. and Schandert, B., Synthetic Metals, 1995, $\underline{70}, 1365$.

20. Xiang, B. and Kevan, L., In "Fullerenes. Recent advances in the chemistry and physics of fullerenes and related materials", ed. K.M. Kadish and R.S. Ruoff., Electrochem. Soc. Proceed., 1994, 24, 981.

21. Rothschild, W.G., J. Am. Chem. Soc., 1972, 94, 8676.

22. Parsons, A.E., J. Mol. Spectrosc., 1961, 6, 201.

23. Koering, J.L., "Spectroscopy of polymers", Chapter 4: Case West. Res. Univ., ACS Professional Reference Book, Amer. Chem. Soc., Washington, 1992.

24. Kato, T., Kodama, T., Oyama, M., Okazaki, S., Shida, T., Nakagawa, T., Matsui, Y., Suzuki, S., Shiromaru, H., Yamauchi, K. and Achiba, Y., Chem. Phys. Letters, 1991, 186, 35 .

25. Dubois, D., Jones, M.T. and Kadish, K.M., J. Am. Chem. Soc., 1992, 114, 6446.

26. Rataiczak, K.D., Koh, W., Subramanian, R., Jones, M.T. and Kadish, K.M., Synthetic Metals, 1993, 55-57, 3137. 
27. Khaled, M.M., Carlin, R.T., Trulove, P.C., Eaton, G.R. and Eaton, S.S., J. Am. Chem. Soc., 1994, 116, 3465.

28. Schell-Sorokin, J., Mehran, F., Eaton, G.R., Eaton, S.S., Viehbeck, A., O'Toole, T.R. and Brown, C.A., Chem. Phys. Letters, 1992, 195, 225.

29. Allemand, P.-M., Srdanov, G., Koch, A., Khemani, K., Wudl, F., Rubin, Y., Diederich, F., Alvarez, M.M., Anz, S.J. and Whetten, R.L., J. Am. Chem. Soc., $1991, \underline{113}, 2780$.

30. Baumgarten, M., Gügel, A. and Gherghel, L., Advanced Materials, 1993, 5, 458.

31. Singh, K.K., Pradeep, T., Morris, D.E., Chen, L. and Acrivos, J.V., Fullerene Science and Technology, 1996, 4, 583.

32. Sariciftci, N.S., Heeger, A.J. and Wudl, F., in "Fullerenes. Recent advances in the chemistry and physics of fullerenes and related materials", ed. K.M. Kadish and R.S. Ruoff., Electrochem. Soc. Proceed., 1995, 10, 499.

(Received: April 8, 1999) 